\title{
Changes in Visual Fields in Normotensive Glaucoma
}

\author{
Veronika Hofschneider ${ }^{1}$, Jan Lestak ${ }^{2 *}$ and Sarka Pitrova ${ }^{2}$ \\ ${ }^{1}$ Eye department, Sumperk Hospital, Czech Republic \\ ${ }^{2}$ Eye Clinics JL FBMI CTU in Prague, Czech Republic \\ *Corresponding author: Jan Lestak, Eye Clinics JL FBMI CTU in Prague, V Hurkach 1296/10, 158 00, Czech Republic
}

\begin{abstract}
ARTICLE INFO
Received: 嵊 July 12, 2019

Published: 㗀 July 22, 2019

Citation: Veronika Hofschneider, Jan Lestak, Sarka Pitrova. Changes in Visual Fields in Normotensive Glaucoma. Biomed J Sci \& Tech Res 19(5)-2019. BJSTR. MS.ID.003364.
\end{abstract}

Keywords: Changes in Visual Fields in Normotensive Glaucoma

\begin{abstract}
To find the effect of prostaglandins and beta blockers on medium-term progression of changes of visual fields in normotensive glaucoma in a retrospective study. We evaluated three groups of patients with normotensive glaucoma (NTG). The first group consisted of 28 eyes of 14 patients ( 8 females and 6 males) of mean age 59 years (37-75 years) who were treated with prostaglandins. The second group consisted of 20 eyes of 10 patients ( 5 females and 5 males) of mean age 64 years (52-79 years) who were treated with beta blockers. The third group consisted of 36 eyes of 18 patients ( 8 females and 10 males) of mean age 57 years (33-75 years) who underwent no ophthalmological therapy. All patients were compensated for cardiovascular status and had no other internal or neurological disease. Visual acuity was 1.0 with a possible correction (less than 3 dioptres) in all patients.

If hypotensive ophthalmological therapy was initiated, it had remained stable for the last five years. In all patients, central corneal thickness (CCT), excavation of the optic nerve papilla (c/d), ganglion cell complex (GCC), retinal nerve fiber thickness (RNFL), pupillary defect (PD) and overall defect (OD) of visual field were monitored by us. Statistical analysis found the highest progression of changes in the visual fields (PD) in patients without therapy $(\mathrm{p}=0.0001)$ and in patients treated with prostaglandins $(\mathrm{p}=0.04)$. In patients who were treated with beta blockers, the progression of changes in the visual fields was statistically significant $(\mathrm{p}=0.7)$. We did not find a statistically significant progression in any group. The correlation analysis found the highest correlation with GCC in PD ( $r=0.33$; $\mathrm{p}=0.44$ ). We did not find any correlation between the evaluated parameters in OD. Our results show that therapy with beta blockers is more convenient for NTG, compared to prostaglandins or no topical therapy.
\end{abstract}

\section{Introduction}

Normotensive glaucoma (NTG) is defined as progressive optic neuropathy with glaucomatous disc of the optic nerve and visual field in which IOP is equal or lower than $21 \mathrm{mmHg}$ [1]. Differences compared to hypertensive glaucoma (HTG) were described in the previous paper [2]. In 2013, we referred to the effects of pharmacological therapy on the progression of changes in the visual fields in hypertensive glaucoma (HTG). We did not find differences between therapy with prostaglandins or beta blockers [3]. Because NTG is pathophysiologically a different disease, we were interested in determining whether the finding would be similar to that of HTG after a 5-year follow-up of the changes in visual fields without local therapy. This was the purpose of our study.

\section{Materials and Methods}

We evaluated three groups of patients with NTG. Diagnosis was determined by means of complex ophthalmology examination, including the IOP curve and electrophysiological examination. The first group consisted of 28 eyes of 14 patients ( 8 females and 6 males) of mean age 59 years (37-75 years) who were treated with prostaglandins. The second group consisted of 20 eyes of 10 patients ( 5 females and 5 males) of mean age 64 years (52-79 years) who were treated with beta blockers. The third group consisted of 36 eyes of 18 patients ( 8 females and 10 males) of mean age 57 years (33-75 years) who underwent no ophthalmological therapy. All patients were compensated for cardiovascular status and had no 
other internal or neurological disease. Visual acuity was 1.0 with a possible correction (less than \pm dioptres) in all patients.

The IOP ranged between $10-15 \mathrm{mmHg}$ in all patients. If hypotensive ophthalmological therapy was initiated, it had been stable for the last five years. In all patients, we monitored CCT, excavation in the papilla (c/d), ganglion cell complex (GCC), thickness of the retinal nerve fibre layer (RNFL), pattern defect (PD) and overall defect (OD) of the visual field. In 2013, changes in the visual fields were approximately the same in all patients. We compared the results of the visual fields after five years, i.e. the results were found in 2018. Central corneal thickness (CCT) was measured, using the ultrasound pachymeter Tomey SP-100. GCC and RNFL, using optic coherence tomography SD-OCT RTvue-100, and the visual filed using the glaucoma fast threshold program with the MEDMONT M 700 device. For statistical consideration, we used the paired test and correlation analysis.

\section{Results}

\section{Patients Treated with Prostaglandins}

Number of patients: 14

Mean age: $58.2 \pm 10.4$

Lowest: 37

Highest: 75

Mean PD 0: $2.77 \pm 2.44$

Mean PD 5: $3.2 \pm 2.5$

$\mathrm{p}=0.04$

Mean OD 0: 2.7 \pm 1

Mean OD 5: 2.8 \pm 1

$\mathrm{p}=0.4$

Therapy

xalatan 9

monopost - 2

taflotan - 2

bimican - 1

System changes

Hypertension - 4

Hypotension - 4

5.2. Patients Treated with Beta Blockers:

Number of patients: 10

Mean age: $57 \pm 10.7$

Lowest: 33
Highest: 75

Mean PD 0: $2.17 \pm 1$

Mean PD 5: 2.2 \pm 1.3

$\mathrm{p}=0.7$

Mean OD 0: $3.2 \pm 0.6$

Mean OD 5: $3.5 \pm 0.9$

$\mathrm{p}=0.4$

Therapy

betoptic - 5

carteol - 5

System Changes

hypertension - 1

hypotension - 2

5.3. Patients without Therapy:

Number of patients: 18

Mean age: $58.2 \pm 10.4$

Lowest: 37

Highest: 75

Mean PD 0: $2.2 \pm 0.7$

Mean PD 5: $2.9 \pm 1.5$

$\mathrm{p}=0.0001$

Mean OD 0: $3.2 \pm 1$

Mean OD 5: $3 \pm 1.4$

$\mathrm{p}=0.24$

System changes

Hypertension - 1

Hypotension - 2

CAD - 2

From the above Table 1, we can see that the GCC variable correlates mostly with the progression of changes in PD ( $r=0.3255$; $\mathrm{p}=0.04$ ). Therefore, it is a proportional correlation. No variable correlates statistically significantly with the progression of changes in OD. Furthermore, it can be concluded that GCC strongly correlates with RNFL ( $\mathrm{r}=0.73 ; \mathrm{p}=0.0001)$ and weakly with $\mathrm{c} / \mathrm{d}(\mathrm{r}=0.32$; $\mathrm{p}=0.05)$. The correlation with CCT is also interesting $(\mathrm{r}=0.3$; $\mathrm{p}=0.009$ ). We found a similar correlation between the changes in visual fields and CCT also in HTG [4]. 
Table 1: Final correlation coefficients' data of the evaluated variables. PD-pattern defect, OD-overall defect, CCT-central corneal thickness, c/d-cup/disc ratio, GCC-ganglion cell complex, RNFL-retinal nerve fibre layer.

\begin{tabular}{|c|c|c|c|c|c|c|}
\hline \multirow{2}{*}{ Variable } & \multicolumn{6}{|c|}{ Correlations (Data) Marked correlations are significant at $\mathrm{p}<0.05000 \mathrm{~N}=86$ (Case wise deletion of missing data) } \\
\hline & PD (before-after) & OD (before-after) & СCT & c/d & GCC & RNFL \\
\hline \multirow{2}{*}{ PD (before-after) } & 1 & 0.1192 & 0.1454 & 0.0123 & 0.3255 & 0.1951 \\
\hline & $\mathrm{p}=---$ & $\mathrm{p}=0.305$ & $\mathrm{p}=0.210$ & $\mathrm{p}=0.916$ & $\mathrm{p}=0.004$ & $\mathrm{p}=0.091$ \\
\hline \multirow{2}{*}{ OD (before-after) } & 0.1192 & 1 & 0.0244 & -0.0319 & 0.0256 & -0.0149 \\
\hline & $\mathrm{p}=0.305$ & $\mathrm{p}=---$ & $\mathrm{p}=0.835$ & $\mathrm{p}=0.785$ & $\mathrm{p}=0.826$ & $\mathrm{p}=0.898$ \\
\hline \multirow{2}{*}{$\mathrm{CCT}$} & 0.1454 & 0.0244 & 1 & -0.0519 & 0.2959 & -0.0259 \\
\hline & $\mathrm{p}=0.210$ & $\mathrm{p}=0.835$ & $\mathrm{p}=---$ & $\mathrm{p}=0.656$ & $\mathrm{p}=0.009$ & $\mathrm{p}=0.824$ \\
\hline \multirow{2}{*}{$c / d$} & 0.0123 & -0.0319 & -0.0519 & 1 & -0.3224 & -0.1662 \\
\hline & $\mathrm{p}=0.916$ & $\mathrm{p}=0.785$ & $\mathrm{p}=0.656$ & $\mathrm{p}=---$ & $\mathrm{p}=0.005$ & $\mathrm{p}=0.151$ \\
\hline \multirow{2}{*}{ GCC } & 0.3255 & 0.0256 & 0.2959 & -0.3224 & 1 & 0.7374 \\
\hline & $\mathrm{p}=0.004$ & $\mathrm{p}=0.826$ & $\mathrm{p}=0.009$ & $\mathrm{p}=0.005$ & $p=---$ & $\mathrm{p}=0.000$ \\
\hline \multirow{2}{*}{ RNFL } & 0.1951 & -0.0149 & -0.0259 & -0.1662 & 0.7374 & 1 \\
\hline & $\mathrm{p}=0.091$ & $\mathrm{p}=0.898$ & $\mathrm{p}=0.824$ & $\mathrm{p}=0.151$ & $\mathrm{p}=0.000$ & $p=--$ \\
\hline
\end{tabular}

\section{Discussion}

According to the Normal-Tension Glaucoma study, the main principle of therapy of NTG is a decrease of the IOP. This study showed that a decrease of the IOP had a positive effect on the progression of this disease, compared to untreated controls with NTG. Progression of changes in the visual fields occurred even after this decrease in $12 \%$ of cases [5]. The most commonly prescribed anti-glaucoma agents used in monotherapy in several studies did not achieve a decrease of the IOP proposed by the Collaborative Normal-Tension Glaucoma study. Prostaglandin analogues (latanoprost and bimatoprost), beta blockers and alpha-adrenergic agonists decrease IOP by $16 \%$ to $20 \%$ during monotherapy $[6,7]$. Administration of dorzolamide/timolol and brimonidine/timolol for 12 weeks resulted in a decrease of the IOP by $20 \%$ and $23.7 \%$, respectively $[8,9]$. Tomita et al. monitored a decrease of IOP for three years, and the changes in visual fields in latanoprost and timolol-maleate. The decrease of IOP was 13-15\% in both groups. Progression of changes in visual fields (MD) for latanoprost was (dB/year) $-0.34 \pm 0.17$ and $-0.10 \pm 0.18$ for timolol. The differences were not statistically significant [10].

Krupin et al. [11] compared the effect of brimonidine and timolol on the changes in the visual fields and found a higher progression in NTG when timolol was used. The authors state that beta blockers can even have a detrimental effect on NTG. Although these conclusions should be interpreted with caution, due to the high number of discontinuations in the brimonidine group, the results suggested that brimonidine had a relatively protective effect on the visual field. Hayreh et al. [12] report that topical beta blockers induce a significant decrease in mean diastolic blood pressure at night, and that patients with NTG treated with beta blockers had visual field progression more frequently than those who did not. They conclude that beta blockers are a risk factor for patients with NTG. This is also the reason why our group treated with beta blockers is so small and timolol-maleate is not used.

The possibilities of pharmacological treatment in progressive cases include betaxolol eye drops, which, in addition to reducing IOP, have a beneficial effect on the optic nerve blood flow. Other beta blockers and adrenergic agents (such as dipivefrin) should be excluded, due to the likelihood of nocturnal systemic hypotension and optic nerve hypoperfusion. Prostaglandin derivates tend to have a higher IOP decreasing effect, which can have a fundamental significance [13]. Carteolol is a non-selective beta blocker with intrinsic sympathomimetic activity (I.S.A.) Carteolol had no effect on nocturnal IOP, but significantly helped to reduce daytime IOP, maximum IOP, mean 24-h IOP, and the 24-h IOP range. The drug exerted no statistically significant effect on the pulse rate [14]. Brinzolamide and betaxolol significantly increased the thickness of choroidal in healthy individuals, while latanoprost had no effect [15]. With regard to the undesirable effects of beta blockers, a study by the authors who monitored 1112 patients with the diagnosis of AV block should be stated.

A permanent pacemaker was implanted in 946 cases (84.3\%) during the follow-up period. Of this number, 13 patients were taking topical beta blockers ( 7 patients applied timolol, 4 betaxolol and 2 cartelol). The mean time of therapy using ophthalmological beta blockers was $30.1 \pm 15.9$ months. Eight patients had a complete $\mathrm{AV}$ block and 5 patients had a high degree of AV block during electrocardiographic study. Following discontinuation of treatment in 10 patients, the block persisted, and a permanent pacemaker had to be implanted. One patient needed implantation of a pacemaker during the follow-up period. Pacemakers were implanted in a total of 11 out of 13 patients [16]. Messner et al. studied the changes in the visual fields in HTG during therapy with timolol and betaxolol. The effect of treatment on the visual fields was better in the 
betaxolol group than in the timolol group $(\mathrm{P}=0.04)$ [17]. Carenini et al. [18] studied pulsatile ocular blood flow (POBF) in patients with HTG treated with timolol and betaxolol.

They found that POBF was significantly decreased during the 12-month observation period in patients treated with timolol, while remaining stable in patients treated with betaxolol [18]. The study by Melena et al. [19] who investigated the possible blockade of calcium entry into the cells on isolated rat retinas, by stimulating the NMDA receptors using anti glaucoma tics (betaxolol, carteolol, levobunolol, timolol, brimonidine, dorzolamide, latanoprost and pilocarpine), is also interesting. We found that beta blockers could affect this process with the highest effect in betaxolol [19]. The neuroprotective effect of betaxolol on isolated rat retinas was also demonstrated by the study of Osborn et al., who investigated the influx of calcium into the cells. They found a significant reduction of the increased $\mathrm{Ca} 2+$ values following the administration of kainite [20]. Both beta blockers (betoptic and carteolol) we evaluated in our studies had a positive effect on the changes in visual fields in NTG. We did not have to change this therapy in any patient during the follow-up period with regard to possible general problems. We are aware of the smaller groups in which we used beta blockers, which is a limitation of this work. Following their effect on the progression of the disease, we will consider a more frequent administration and, perhaps after five years, will perform a similar assessment.

\section{Conclusion}

Our results show that therapy with beta blockers (betaxolol and carteolol) is more suitable for patients with NTG vs prostaglandins or without topical therapy.

\section{References}

1. Lee BL, Bathija R, Weinreb RN (1998) The definition of normal-tension glaucoma. J Glaucoma 7(6): 366-371.

2. Lestak J, Pitrova S, Nutterova E, Bartosová L (2019) Normotensive glaucoma vs hypertensive glaucoma - summary. Cesk Slov Oftal 75: 5560.

3. Lestak J, Pitrova S, Rozsival P (2013) Comparison of b-Blockers and Prostaglandins Treatments in Primary Open-Angle Glaucoma. J Clin Exp Ophthalmol 4: 294

4. Lestak J, Rozsival P (2012) The Influence of Corneal Thickness on Progression of Hypertensive Glaucoma. J Clin Exp Ophthalmol 3: 245.

5. (1998) Comparison of glaucomatous progression between untreated patients with normal-tension glaucoma and patients with therapeutically reduced intraocular pressures. Am J Ophthalmol 126(4): 487-497.
6. Cheng JW, Cai JP, Wei RL (2009) Meta-analysis of medical intervention for normal tension glaucoma. Ophthalmology 116(7): 1243-1249.

7. Fung AT, Reid SE, Jones MP, Healey PR, Mc Cluskey PJ, et al. (2007) Meta-analysis of randomised controlled trials comparing latanoprost with brimonidine in the treatment of open-angle glaucoma, ocular hypertension or normal-tension glaucoma. Br J Ophthalmol 91(1): 6268.

8. Kim TW, Kim M, Lee EJ, Jeoung JW, Park KH (2014) Intraocular pressurelowering efficacy of dorzolamide/timolol fixed combination in normaltension glaucoma. J Glaucoma 23(5): 329-332.

9. Kim JM, Kim TW, Kim CY, Kim HK, Park KH (2016) Comparison of the intraocular pressure-lowering effect and safety of brimonidine/timolol fixed combination and $0.5 \%$ timolol in normal-tension glaucoma patients. Jpn J Ophthalmol 60(1): 20-26.

10. Tomita G, Araie M, Kitazawa Y, Tsukahara S (2004) A three-year prospective randomized and open comparison between latanoprost and timolol in Japanese normal-tension glaucoma patients. Eye 18(10): 984 989.

11. Krupin T, Liebmann JM, Greenfield DS, Ritch R, Gardiner S (2011) LowPressure Glaucoma Study Group. A randomized trial of brimonidine versus timolol in preserving visual function: results from the LowPressure Glaucoma Treatment Study. Am J Ophthalmol 151(4): 671-681.

12. Hayreh SS, Podhajsky P, Zimmerman MB (1999) Beta-blocker eyedrops and nocturnal arterial hypotension. Am J Ophthalmol 128(3): 301-309.

13. Kanski JJ, Bowling B, Nischal K, Pearson R (2011) ( $7^{\text {th }}$ edn). Clinical Ophthalmology: A Systematic Approach pp. 346-348.

14. Nakamoto K, Yasuda N (2010) Effect of carteolol hydrochloride on 24hour variation of intraocular pressure in normal-tension glaucoma. Jpn J Ophthalmol 54(2): 140-143.

15. Okutucu M, Findık H, Arslan MG (2019) Direct and crossover effects of brinzolamide, betaxolol, and latanoprost on choroidal thickness. Cutan Ocul Toxicol 38(2): 196-200.

16. Özcan KS, Güngör B, Osmonov D, Tekkeșin AI, Altay S, et al. (2015) Management and outcome of topical beta-blocker-induced atrioventricular block. Cardiovasc J Afr 26(6): 210-213.

17. Messmer C, Flammer J, Stümpfig D (1991) Influence of betaxolol and timolol on the visual fields of patients with glaucoma. Am J Ophthalmol 112(6): 678-681.

18. Carenini AB, Sibour G, Boles Carenini B (1994) Differences in the longterm effect of timolol and betaxolol on the pulsatile ocular blood flow. Surv Ophthalmol 38: 118-124.

19. Melena J, Stanton D, Osborne NN (2001) Comparative effects of antiglaucoma drugs on voltage-dependent calcium channels. Graefes Arch Clin Exp Ophthalmol 239(7): 522-530.

20. Osborne NN, Cazevieille C, Carvalho AL, Larsen AK, De Santis L (1997) In vivo and in vitro experiments show that betaxolol is a retinal neuroprotective agent. Brain Res 751(1): 113-123. 


\section{ISSN: 2574-1241}

DOI: 10.26717/BJSTR.2019.19.003364

Jan Lestak. Biomed J Sci \& Tech Res

(C) This work is licensed under Creative

Submission Link: https://biomedres.us/submit-manuscript.php

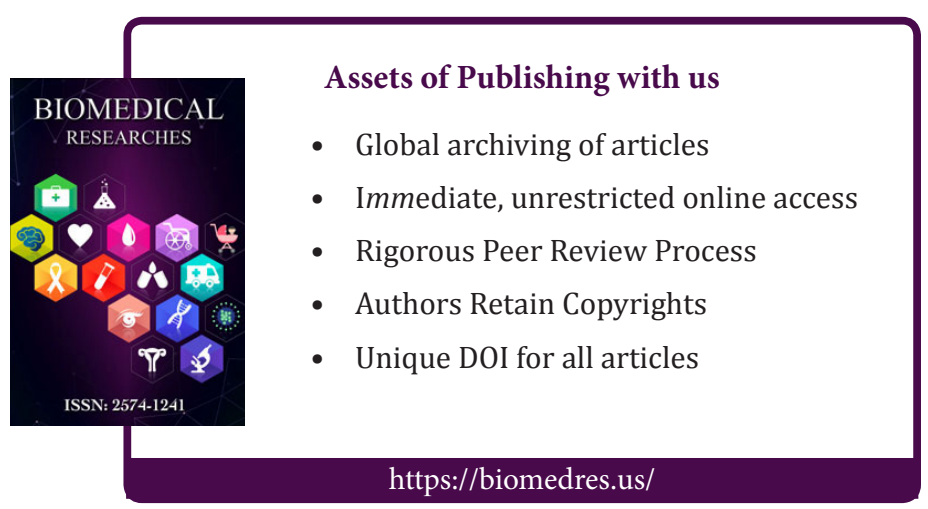

